\title{
REFLEXOS DA FORMAÇÃO HUMANÍSTICA NO CURSO DE ENGENHARIA DE COMPUTAÇÃO
}

Marcus Aldrey Soares dos Santos; David Moises Barreto dos Santos';

1. Bolsista PIBIC/CNPq, Graduando em Engenharia de Computação, Universidade Estadual de Feira de Santana, email: marcusaldrey@gmail.com

2. Orientador, Departamento de Ciências Exatas, Universidade Estadual de Feira de Santana, e-mail: davidmbs@gmail.com

PALAVRAS-CHAVE: formação humanística; logoterapia; educação.

\section{INTRODUÇÃO}

Todo ser humano é condicionado por diversos fatores, seja em sua dimensão biológica, psíquica ou sociológica, porém, na visão antropológica de Viktor Frankl, além das dimensões supracitadas, o ser humano ainda possui outra dimensão denominada noética, que engloba as demais (biopsicosocial) e na qual se encontra suas potencialidades: pensar, refletir, poder de decisão, criatividade, senso ético, amor, busca de sentido, liberdade, responsabilidade, etc (FRANKL, 2011; LUKAS, 1989). É a dimensão que oferece uma visão integral do ser humano (biopsicosocial- noético), não o fragmentando neste ou naquele ângulo, e que é a dimensão especificamente humana. Nenhum outro ser vivo a possui. Nesse contexto, Viktor Frankl defende que a busca por realização de sentido na vida, através da dimensão noética, é a principal força motivadora do ser humano. Quando ela é frustrada acaba por provocar uma sensação de de futilidade, falta de sentido e/ou vazio interior - denominada frustração existencial (FRANKL, 2011). Viktor Frankl afirmou que tal frustração é a neurose de nossa época, que, particularmente, demonstra estar bastante presente entre os jovens, "É compreensível que especialmente a geração jovem padece mais da sensação de falta de sentido, o que é corroborado pelos resultados de pesquisa empíricos" (FRANKL, 2007, p. 101). Esta frustração ainda é marcada por uma tríade sintomática: depressão, agressividade e dependência de drogas (FRANKL, 2008). Deste modo, em uma época marcada pelo vazio existencial, a prática pedagógica também deve ser capaz de prevenir e combater tal vazio. (GARCÍA, 2009).

\section{MATERIAL E MÉTODOS OU METODOLOGIA (ou equivalente)}

Um total de 246 sujeitos fizeram parte desse estudo, sendo eles alunos de 7 semestres diferentes que realizaram uma análise do livro "Em busca sentido", de Viktor Frankl. O período analisado foi do semestre 2013.2 até o 2017.1. Como instrumento da pesquisa foi feita uma coleta dos dados de um relatório com um questionário contendo 3 perguntas acerca da experiência do aluno com o livro "Em busca de sentido: um psicólogo no campo de concentração", onde cada estudante deveria discutir e descrever sua percepção em relação à leitura. Na Tabela 1 encontra-se a descrição do questionário. A atividade foi proposta no início do semestre e discutida em sala de aula de maneira continuada.

Tabela 1. Roteiro do questionário aplicado aos alunos. 


\begin{tabular}{ll}
\hline 1 & $\begin{array}{l}\text { Quais as ideias principais do autor que você percebeu? Indique e } \\
\text { comente. } \\
\text { Aponte e comente três aspectos que mais lhe chamaram a } \\
\text { atenção. }\end{array}$ \\
Indique três aspectos (que podem coincidir ou não com os \\
listados na questão anterior) e a partir deles discuta de que modo \\
eles podem contribuir com sua realidade, sua visão de mundo.
\end{tabular}

O estudo das respostas das questões foi feito através da análise de conteúdo (BARDIN, 2000) e foi utilizado o software NVIVO10. As respostas foram codificadas através de categorias pré-definidas de acordo com os conceitos da logoterapia, porém, novas categorias foram surgindo no processo de análise sempre que muitas respostas contemplavam um aspecto em comum do livro.

\section{RESULTADOS E/OU DISCUSSÃO (ou Análise e discussão dos resultados)}

A tabela 3 mostra quais foram as ideias principais do livro mais identificadas pelos alunos.

Tabela 2. Ideias principais do livro mais identificadas pelos alunos

\begin{tabular}{lcc}
\hline \multicolumn{1}{c}{ Categoria } & $\begin{array}{c}\text { Frequência } \\
\text { absoluta }\end{array}$ & $\begin{array}{c}\text { Frequência } \\
\text { relativa (em \%) }\end{array}$ \\
\hline Sentido de vida & 104 & 42,3 \\
Ênfase na questão psicológica & 79 & 32,1 \\
Cotidiano no campo de concentração & 74 & 30 \\
\hline
\end{tabular}

A categoria "sentido de vida", ideia principal do livro mais identificada pelos alunos, reúne todos os trechos em que os alunos acentuaram que ter um propósito para continuar vivendo é o que faz com que os prisioneiros consigam superar as adversidades do campo de concentração. A frequência com que essa categoria foi identificada nos mostra que os alunos conseguiram captar a ideia principal do livro. Em um dos textos analisados, um aluno diz "a existência da pessoa é o principal, pois cada indivíduo tem uma meta, um sentido para continuar vivo, e ele sabia que não podia entregar os pontos". O próprio autor, Viktor Frankl, deixa claro que o ponto principal do livro é a ideia de sentido de vida como força motriz, "somente entregava os pontos aquele que não tinha mais em que se segurar interiormente (...) A maioria dispunha de algo que os sustentava, e geralmente se tratava de um pedaço de futuro" (FRANKL, 2008).

A ênfase na questão psicológica foi o segundo aspecto mais observado pelos alunos. A intenção do autor foi "descrever com clareza e riqueza de detalhes os aspectos psicológicos da sua experiência no campo de concentração, bem como o ambiente e as experiências dos outros prisioneiros" (FRANKL, 2008).

Sendo uma narração do tempo em que o autor permaneceu no campo de concentração, o cotidiano no campo é naturalmente uma das temáticas principais do livro e foi o terceiro conteúdo mais apontado pelos estudantes como tema central do livro. O comportamento dos prisioneiros, como eles comiam, dormiam, o que faziam quando não estavam trabalhando, todos esses aspectos são abordados no livro e foram assinalados pelos alunos nas respostas, na maioria das vezes ressaltando as situações terríveis em que eles viviam. 
A tabela 3 mostra os aspectos que mais chamaram atenção dos alunos, junto às suas respectivas frequências e exemplos, retirados das respostas dos estudantes.

Tabela 3. Pontos que mais chamaram atenção dos alunos

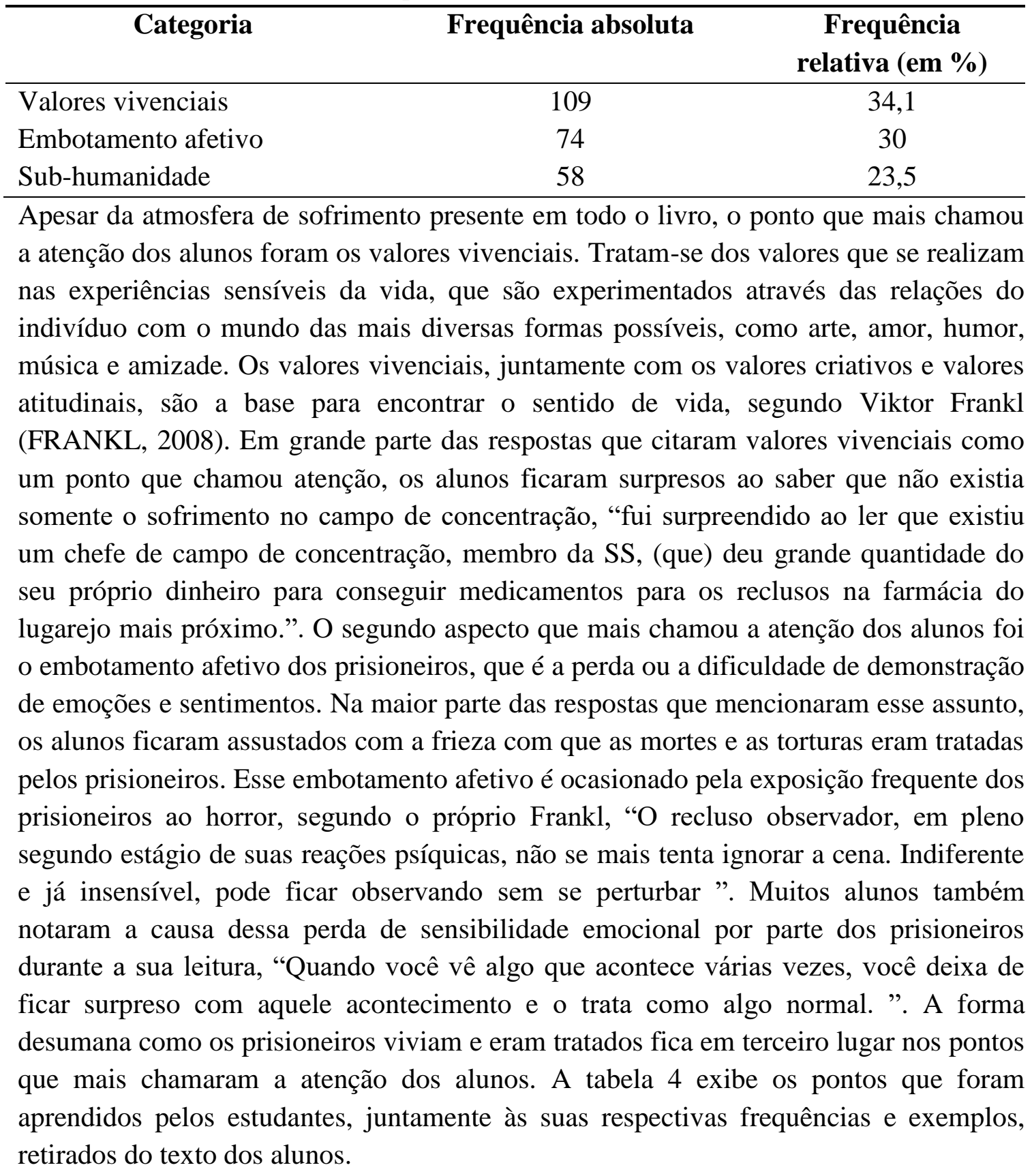

Tabela 4. Pontos mais aprendidos pelos alunos

\begin{tabular}{lcc}
\hline Categoria & Frequência absoluta & $\begin{array}{c}\text { Frequência } \\
\text { relativa (em \%) }\end{array}$ \\
\hline Valor vivencial & 97 & 39 \\
Valor atitudinal & 71 & 28,8 \\
Vontade de sentido & 44 & 17,8 \\
\hline
\end{tabular}


O fator que mais gerou aprendizado para os alunos foram os já citados valores vivenciais. Observar que mesmo em uma situação tão horrível como um campo de concentração, os prisioneiros ainda conseguiam valorizar experiências como o humor, a arte, a amizade, o amor e a solidariedade, fez os alunos enxergarem as interações com o mundo de uma forma mais positiva. Um dos alunos diz: "[...] expande minha visão de mundo ao mostrar que apesar das circunstâncias, a atividade artística (em suas diversas formas) pode e deve funcionar como válvula de escape, como forma de expressão, como um meio de deixar fluir sentimentos".

O segundo ponto mais apontado pelos alunos na resposta sobre o que mais aprenderam foram os valores atitudinais. Esses valores estão relacionados a tomada de posição por parte do indivíduo frente aos problemas inevitáveis da vida, definidos por Frankl como tríade trágica (sofrimento, culpa e morte). Segundo Viktor Frankl: "A única coisa que você não pode tirar de mim é o caminho que eu escolhi para responder ao que você faz para mim. A última liberdade é escolher que atitude tomar em qualquer circunstância." (FRANKL, 2008). Esse pensamento de Frankl pode ser observado com frequência nas respostas, "Mesmo quando as coisas estiverem extremamente ruins, sempre é possível ver algo proveitoso", disse um aluno. A terceira temática que mais proporcionou aprendizado aos alunos foi a vontade de sentido, sendo esta a motivação primária do ser humano de buscar um sentido em sua vida. "Todo ser humano precisa dotar-se de objetivos e propósitos a serem seguidos. Muitas vezes em nossa vida, nos deparamos com situações de desânimo e desmotivação, com a ideia de que tudo está perdido ou não vale à pena. $\mathrm{O}$ que está por vir é incerto, mas cabe a nós acreditar e fazer o nosso melhor hoje para alcançar o futuro sonhado “, escreveu um aluno.

\section{CONSIDERAÇÕES FINAIS (ou Conclusão)}

Apesar de todo sofrimento encontrado no livro, os alunos conseguiram compreender e se conectar com a mensagem central dele: do sentido de vida como principal fator protetor da vida. Os estudantes conseguiram refletir e aprender sobre sentidos e valores, especialmente, vivenciais e atitudinais, fortemente abordados na logoterapia. Em função disso, pode-se concluir que o livro é um recurso pedagógico capaz de promover aprendizado humanístico-existencial entre os educandos, inclusive prevenindo o vazio existencial.

\section{REFERÊNCIAS}

BARDIN, L. Análise de Conteúdo. Lisboa: Edições 70, 2000.

FRANKL, V. E. Em busca de sentido: um psicólogo no campo de concentração. Petrópolis: Vozes, 2008.

FRANKL, V. E. A vontade de sentido: fundamentos e aplicações da logoterapia. São Paulo: Paulus, 2011.

GARCÍA, L. A. DE. La logoterapia es más que una terapia: hacia una propuesta educativa. Revista Mexicana de Logoterapia, 2009.

LUKAS, E. Logoterapia: a força desafiadora do espírito. São Paulo: Edições Loyola, 1989.

FRANKL, V. E. A presença ignorada de Deus. São Leopoldo, Petrópolis: Sinoidal, Vozes, 2007. 